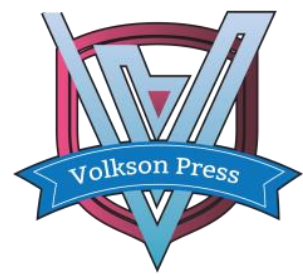

Contents List available at VOLKSON PRESS

Economics \& Management Innovations(EMI)

DOI : http://doi.org/10.26480/icemi.01.2017.33.35

\title{
Concept and Imposition Scheme of Vacancy Tax and Tax Rate Design
}

\section{Charl Chan1, Jian Ping23, *}

1School of Economics, Liaoning University of Technology, 121001, Jinzhou, Liaoning, China

2Department of Public Administration, Party School of The Liaoning committee of CPC, 110004,

Shenyang, Liaoning, China

3School of International Studies, Liaoning University, 110036, Shenyang, Liaoning, China

*pingjian330@126.com

This is an open access article distributed under the Creative Commons Attribution License, which permits unrestricted use, distribution, and reproduction in any medium, provided the original work is properly cited.

\section{ARTICLE DETAILS}

\section{Article History:}

Received 02 october 2017

Accepted 06 october 2017

Available online 11 october 2017

Keywords:

vacancy tax, housing price, tax rate design.

\section{ABSTRACT}

There has long been controversy over the levitation of the vacancy tax in the academic world. This paper believes that the collection of the vacancy tax should be made to improve the utilization efficiency of property resources. On that basis, the paper puts forward a dual-standard taxation regime with the number and size of houses as the tax base, and examines the influence mechanism of the vacancy tax on housing rental and sale prices. At last, this paper proposes a tax rate for reference and concludes that a progressive tax rate may approximate the average housing rental-sale ratio.

\section{Introduction}

Property tax mainly represents a tax levied on housing tenure and is also referred to as the vacancy tax hereafter. Three major opinions prevail internationally about its nature and function[1][2], namely, the vacancy tax is in essence a type of yield tax that pays for public services to boost the local revenue; it functions to adjust income distribution; the vacancy tax can regulate the real estate market. Infrastructure in most cities of our country is far from being solid and urban functions are yet to be improved. Urban planning do upvalue the real estate by a large margin in some areas, but that does not mean that residents there have obtained tangible benefits. This is due to the fact that they are just passive beneficiaries and that houses used for self-occupation will not bring them any extra gains. If the vacancy tax is collected to adjust income distribution, it must be ensured beforehand that the real estate constitutes the main assets of high net-worth individuals. As the real estate market takes on different landscapes in different regions, it is obviously unfair to tax areas where the housing price fluctuates a lot or presents to be too high only. Vacancy tax involves also the differences between active emptying and passive emptying in terms of taxation scope, as well as the demands of the rental housing market[3]. Comprehensively speaking, China's purpose of collecting a vacancy tax should be to improve the utilization of real estate resources, reduce vacancy rate, promote the rational allocation of housing resources and help to strike a supply-demand balance in both housing rental and trade markets.

\section{Implementation of vacancy tax}

Although a size-based vacancy tax is now preferred, this paper holds that number of houses should also be taken into consideration[4]

\subsection{Double-standard tax implementation scheme}

This paper believes that the total housing size should be taken as the threshold first and the number of houses as a further reference. On the basis of this, a gradient vacancy rate should be formulated to accommodate increasing size and number of houses. Meanwhile, the reason why this paper refrains from a unified size-based vacancy tax is that we think that residents' diverse housing needs, needs in high-end housing included, should be meet. The vacancy tax shall not render any preference to the high net-worth group. Therefore, if there are two individuals whose housing space are of the same size, the one who has a larger number of houses will face a heavier tax burden than the other. In other words, a size-based vacancy tax and a number-based one will come with different tax rates. Assume that: $\mathrm{S}$ denotes the housing size, Si the total housing size of the $\mathrm{i}$-th individual; $\mathrm{N}$ the number of houses, $\mathrm{Ni}$ the total number of houses owned by the i-th individual, nij the j-th house owned by the $i$-th individual and $t$ the tax rate. Let us first introduce two dummy variables DS and DN and suppose that $\mathrm{S}^{*}$ and $\mathrm{N}^{*}$ represent the threshold of tax exemption, then we get:

$$
D_{S}=\left\{\begin{array}{ll}
0 & S_{i} \leq S^{*} \\
1 & S_{i} \mathrm{f} S^{*}
\end{array} \quad D_{N}= \begin{cases}0 & j \mathrm{p} N^{*} \\
1 & j \geq N^{*}\end{cases}\right.
$$

When one's housing size is smaller than that requested by tax exemption, the dummy variable equals 0 ; on the other way around, it gets 1 . By the same token, when the number of houses owned by an individual is smaller than that requested by tax exemption, the dummy variable equals 0 ; on the other way around, it gets 1 .

\subsection{Tax calculation formula}

Do not print page numbers: Please number each sheet toward the middle near the bottom (outside the typing area) with a soft pencil. Regardless of other transaction costs generated during taxing, we have worked out the total amount of vacancy tax due from urban residents in line with the scheme above. The formula goes as follows:

$T_{i}=D_{S} D_{N} \sum_{j=N^{*}}^{N} p_{i j} t_{n_{j}}+D_{S}\left(1-D_{N}\right) \sum_{1 \mathrm{p} j \mathrm{p} N^{*}}^{N} p_{i j} t_{s}$

$p$ represents the estimated price of the $j$-th house owned by the $i$-th individual and it ideally will be $i j$

tantamount to the actual selling price. $t_{n j}$ represents the tax rate levied on the $j$-th house based on the

number. It is noteworthy here that this is not particular to any single one but applies to everyone under the same conditions. And that's why there is no subscript ${ }^{i} . t_{S} j$ represents the tax rate levied on the $\mathrm{j}$-th house based on the size.

We strictly define $t$ as the monotone increasing function of both $n j$ and $s j$. A strict monotone increasing function means that the gradient tax rate increases with more housing resources consumed. For instance, if one has two houses that are eligible for taxation, the smaller one will correspond to a $\mathrm{j}$ that values less and, therefore, a lower tax rate. It's 
unreasonable that the bigger one employs the lower tax rate first. In addition, the large but low-priced houses are geographically poor in general. This scheme tends to believe that houses for self-use will usually be located at where geographical conditions are more favorable. That's why we define the tax rate as the monotone increasing function of the size rather than of the estimated price. The imposition of the vacancy tax should not add any financial weight to the residents. On the contrary, it should work to alleviate the irrational use of housing resources. This formula excludes the possibility that a number-based and a sizebased vacancy tax will go simultaneously. It also stipulates that taxing will be initiated only when one's total housing size overtakes that requested by tax exemption and that one-house-only owner will be taxfree no matter how large the house is. The cost of a personally-owned house will equal to the total payable tax and the interface operation can be achieved through the information management system.

\section{Impacts of the tax rate on housing prices}

The rental income of the $i$-th house owner is denoted as $R_{i}$. Let us assume that he/she owns the house consecutively when $R_{i}$ f $T_{i}$ and vice versa. Then, if $R_{i}=T_{i}$, we may deduce

$$
R_{i}= \begin{cases}\sum_{\operatorname{lp} j \mathrm{p} N^{*}}^{N} p_{i j} t_{s_{j}} & D_{N}=0 \\ \sum_{j=N^{*}}^{N} p_{i j} t_{n_{j}} & D_{N}=1\end{cases}
$$

That the collection of the real estate tax will create alterations on housing prices has also caused extensive disputes. This paper holds that the way in which the tax rate works on housing prices will be in line of the law of supply and demand. That being said, any potential alterations in the external environment of the property market resulted from taxation will ultimately be attributed to a changing real estate supply and demand. Since differentiation has been quite evident in many cities, we should grasp the defining characteristics of the market in different regions and accordingly explore the impacts of the vacancy tax on housing prices. This paper focuses mainly two aspects:

\subsection{When the rental market is adequate on the demand side}

As the tax rate increases, the house owner faces greater costs and he/she can keep possessing it or opt to sell it out. If the rental market is adequate on the demand side, the growing rent will not introduce variations to the effective supply of houses for renting but rental prices will rise. Therefore, the house owner obtains a higher surplus value. Specifically speaking, the rising rent will lift the selling/buying prices of houses in two ways. On the one hand, some people will shift from the rental market to the transaction market and the house purchasing demands will climb as a result. Coupled with the fact that housing supplies may be cut down as fewer houses will go to the transaction market, house sale prices will consequently be on a rise. On the other hand, increases in rental prices themselves forebode an improved housing transaction price. In the perspective of income valuation, the higher the rent is, the greater the valuation of houses will be. It's noteworthy that the appreciation in asset value hereby is regarded as the natural appreciation of the rent and, therefore, the natural appreciation in asset value is not taken into account in this paper.

\subsection{When the rental market is inadequate on the demand side}

In face of the boosted tax rate, one has to raise the rental price to maintain a balanced receipt and payments. However, not all the markets are resilient enough to accommodate policy changes. When the rental market is inadequate on the demand side and the needs to raise the rent cannot be met, the house owner, as well, has two options, namely, to keep the house or sell it out. In this case, the rent rises will lower the house transaction prices in two ways. Firstly, as costs surpass earnings on the basis of the existing rent, the house owner prefer to sell the house out. In doing so, housing supplies in the transaction market will improve and housing selling/buying prices will decline. Secondly, even when one increases investments in house holding, the rental price will not grow nor will the market enhance the current or future housing valuation. A variational vacancy tax rate will help the housing rental and transaction market to convert fromone to the other and strike a balance on the whole.

\section{Tax Rate Design}

Assume that the average sale price of houses in cities be marked as $P$, average rent as $R$ and rental-sale ratio as a, then $a=R / P$. In this paper, the average rent in cities equals approximately to the average payment that each tenant pays for each of his/her houses rented from the owner. And that also applies to the average house owning cost. Suppose that the number of the house registrants to be taxed be represented by $\mathrm{G}$ and that of houses

the $\mathrm{i}$-th individual needs to tax for by ni. It is hereby hypothesized $\mathrm{i}=\mathrm{nn}$, implying that none will fall below the threshold of corresponding taxes. Based on the equation of house owning costs, we may deduce:

$\sum_{i=1}^{G} T_{i}=D_{S} D_{N} \sum_{i=1}^{G} \sum_{j=N^{*}}^{N} p_{i j} t_{n_{j}}+D_{S}\left(1-D_{N}\right) \sum_{i=1}^{G} \sum_{1 \mathrm{p} j \mathrm{p} N^{*}}^{N} p_{i j} t_{s_{j}}$

Based on $\sum_{i=1}^{G} R_{i}=\sum_{i=1}^{G} T_{i}$, we come to:

$\sum_{i=1}^{G} R_{i}=D_{S} D_{N} \sum_{i=1}^{G} \sum_{j=N^{*}}^{N} p_{i j} t_{n_{j}}+D_{S}\left(1-D_{N}\right) \sum_{i=1}^{G} \sum_{1 \mathrm{p} j \mathrm{p} N^{*}}^{N} p_{i j} t_{s_{j}}$

To further unfold it, we arrive at:

$$
\begin{gathered}
\sum_{i=1}^{G} \sum_{j=N^{*}}^{N} p_{i j} t_{n^{*}}= \\
=\left[\left(p_{1 N^{*}} t_{n_{N^{*}}}+\mathrm{L}+p_{1 N} t_{n_{N}}\right)+\mathrm{L}+\left(p_{G N^{*}} t_{n_{N^{*}}}+\mathrm{L}+p_{G N} t_{n_{N}}\right)\right] \\
=\left[t_{n_{N^{*}}}\left(p_{1 N^{*}}+\mathrm{L}+p_{G N^{*}}\right)+\mathrm{L}+t_{n_{N}}\left(p_{1 N}+\mathrm{L}+p_{G N}\right)\right] \\
\sum_{i=1}^{G} \sum_{\mathrm{pp} j \mathrm{p} N^{*}}^{N} p_{i j} t_{s_{j}}=\left[\left(p_{12} t_{s_{2}}+\mathrm{L}+p_{1 N} t_{s_{N}}\right)+\mathrm{L}+\left(p_{G 2} t_{s_{2}}+\mathrm{L}+p_{G N} t_{s_{N}}\right)\right] \\
=\left[t_{s_{2}}\left(p_{12}+\mathrm{L}+p_{G 2}\right)+\mathrm{L}+t_{s_{N}}\left(p_{1 N}+\mathrm{L}+p_{G N}\right)\right]
\end{gathered}
$$

To divide each side of equation (4) by $G$, then we get the average rental income for each houtse owner that is expressed as:

$$
\begin{array}{r}
\bar{R}=D_{S} D_{N} \frac{1}{G}\left[t_{n_{N^{*}}}\left(p_{1 N^{*}}+\mathrm{L}+p_{G N^{*}}\right)+\mathrm{L}+t_{n_{N}}\left(p_{1 N}+\mathrm{L}+p_{G N}\right)\right] \\
+D_{S}\left(1-D_{N}\right) \frac{1}{G}\left[t_{s_{2}}\left(p_{12}+\mathrm{L}+p_{G 2}\right)+\mathrm{L}+t_{s_{N}}\left(p_{1 N}+\mathrm{L}+p_{G N}\right)\right]
\end{array}
$$

Judging from equation (2) and (5), we may infer that the average rental income for each owner's each house is expressed as:

$R=\frac{\bar{R}}{n}= \begin{cases}\frac{1}{n} \frac{1}{G}\left[t_{s_{2}}\left(p_{12}+\mathrm{L}+p_{G 2}\right)+\mathrm{L}+t_{s_{N}}\left(p_{1 N}+\mathrm{L}+p_{G N}\right)\right] & D_{N}=0 \\ \frac{1}{n} \frac{1}{G}\left[t_{n_{N^{*}}}\left(p_{1 N^{*}}+\mathrm{L}+p_{G N^{*}}\right)+\mathrm{L}+t_{n_{N}}\left(p_{1 N}+\mathrm{L}+p_{G N}\right)\right] & D_{N}=1\end{cases}$

- $\mathrm{t}$ The prices of $j$-th house for $\mathrm{G}$ individuals average as:

$$
\overline{p_{j}}=\frac{1}{G}\left(p_{1 j}+\mathrm{L} p_{G j}\right)
$$

Then,

$$
R=\frac{\bar{R}}{n}= \begin{cases}\frac{1}{n}\left(t_{s_{2}} \overline{p_{2}}+\mathrm{L}+t_{s_{N}} \overline{p_{N}}\right) & D_{N}=0 \\ \frac{1}{n}\left(t_{n_{N^{*}}} \overline{p_{N^{*}}}+\mathrm{L}+t_{n_{N}} \overline{p_{N}}\right) & D_{N}=1\end{cases}
$$

We assume that $t$ be the monotonically increasing function of

small-sized house will be subjected to a low tax rate. Then, if the price represents also the monotonically increasing function of $n_{i}$ and $s_{i}$, the average sale price of houses that are eligible to be taxed will increase as the size enlarges. Then, we have $\overline{p_{2}} \mathrm{pL} \overline{\mathrm{p}} \overline{p_{N}}$. By combining $a=R / P$ and equation (7), we may get the weighted average of house sale prices with a progressive tax rate expressed as:

$a= \begin{cases}\frac{1}{n P}\left(t_{s_{2}} \overline{p_{2}}+\mathrm{L}+t_{s_{N}} \overline{p_{N}}\right) & D_{N}=0 \\ \frac{1}{2}\left(t_{n_{N^{*}}} \overline{p_{N^{*}}}+\mathrm{L}+t_{n_{N}} \overline{p_{N}}\right) & D_{N}=1\end{cases}$

Equation (8) indicates that the weighted average of the house sale prices should equal to the rental-sale ratio when housing costs are roughly equivalent to earnings. Yet, equation (8) is far from being handy for us to determine the scope of the progressive tax rate. In fact, we have no idea of the qualities or prices of houses that varied tax rates correspond to. Let us assume that that the average price of houses eligible for taxation be not necessarily positively related to the size but depend also on the location, then we may conclude that the small-sized but high-priced houses will be less densely distributed as they are situated farther from the central city. The opposite applies to the large-sized but low-priced ones. As the house price corresponding to each tax rate can be taken as a sample, then we will have $n$ samples in total. According to the central limit theorem and the law of large numbers, when the sample is quantitatively enough, the sample mean represents the unbiased estimate of the population mean. Therefore, we may conclude that the average price of the $j$-th house is almost no different from the average urban house price. In other words, $p_{j} \quad P$. Then, we reach: 
$R= \begin{cases}\frac{1}{n} P\left(t_{s_{2}}+\mathrm{L}+t_{s_{N}}\right) & D_{N}=0 \\ \frac{1}{n} P\left(t_{n_{N^{*}}}+\mathrm{L}+t_{n_{N}}\right) & D_{N}=1\end{cases}$

By combining $=D 5 / 3$ and equation (9), we conclude that:

$a P= \begin{cases}\frac{1}{n} P\left(t_{s_{2}}+\mathrm{L}+t_{s_{N}}\right) & D_{N}=0 \\ \frac{1}{n} P\left(t_{n_{N^{*}}}+\mathrm{L}+t_{n_{N}}\right) & D_{N}=1\end{cases}$

Namely:

$$
a= \begin{cases}\overline{t_{s}} & D_{N}=0 \\ \overline{t_{n}} & D_{N}=1\end{cases}
$$

Then, $=\mathbb{D} s$ inferred which implies that the average of the progressive tax rate is roughly equal to the rental-sale ratio. Yet, it makes sense when housing incomes are basically equivalent to payments. More importantly, the equitation may constitute a reference for us in designing the tax rate. If there is a reasonable or internationally accepted interval value of rental-sale ratio, then it could be borrowed to China's tax rate determination. At this rate, utilization of property resources will be bettered and the housing market will be brought within control so that a balance will be struck between the rental market and the transaction market. Yet, tax policies can be adjusted to cater to cities with different rental-sale ratio expectations and the dynamic housing market.
Furthermore, both the arithmetic average and the weighted average could be to applied to check the scope of progressive tax rate.

\section{Conclusions}

The levitation of the vacancy tax should be made to improve the utilization efficiency of housing resources. A threshold size should be set for vacancy tax imposition and then the corresponding tax base and progressive tax rate can be decided on the basis of the number of houses. Vacancy tax collection will introduce different alterations to variously-featured housing markets. The arithmetic average or weighted average of the vacancy rate should best approximate the rental-sale ratio. Nevertheless, the exact progressive tax rate remains to be studied further.

\section{References}

[1] Yan Da and Yang Bo. The effect of Reform of the property tax system on the real estate market in China. Journal of Southeast University(Philosophy and Social Science) (s1). (15)(2013),p13-16.

[2] An Tifu and Ge Jing. Related Issues on the Legislation of Real Estate Tax. Finance \& Trade Economics. (8) (2014), p5-12.

[3] Shi jiangang and Chen Chao. Research on regional heterogeneity of Chinese government intervention effects in the housing market. Shanghai: Tongji University Press 2016.

[4] Chao Chen and Jian Ping. Vacancy Tax Levying Algorithm and System Design. RISTI - Iberian Journal of Information Systems and Technologies, V2016, nE9(2016), p14-20. 